\title{
Public health in interwar England and Wales: did it fail?
}

\section{Martin Gorsky}

Centre for History in Public Health. London School of Hygiene and Tropical Medicine martin.gorsky@Ishtm.ac.uk

Dynamis

[0211-9536] 2008; 28: 175-198
Fecha de recepción: 2 de noviembre de 2007

Fecha de aceptación: 13 de febrero de 2008

SUMMARY: 1.-Public health in interwar local government. 2.-The historiography of interwar public health. 3.-Public health and population health. 4.-Did public health fail? A case study from the South-West. 5.-Conclusion.

ABSTRACT: British historians initially saw the interwar period as a "golden age» for public health in local government, with unprecedented preventive and curative powers wielded by Medical Officers of Health (MOsH). In the 1980s Lewis and Webster challenged this reading, arguing that MOsH were overstretched, neglectful of their «watchdog» role and incapable of formulating a new philosophy of preventive medicine. The article first details this critique, then reappraises it in the light of recent demographic work. It then provides a case study of public health administration in South-West England. Its conclusion is that some elements of the Lewis/Webster case now deserve to be revised.

PALABRAS CLAVE: Salud pública, administración local, Inspector de higiene, medicina preventiva.

KEYWORDS: Public health, local government, Medical Officer of Health, preventive medicine.

Proposals in 1944 for Britain's National Health Service (NHS) promised it would: «(...) encourage a new attitude to health - the easier obtaining of advice early, the promotion of good health rather than only the treatment of bad» ${ }^{1}$. Similarly, the architect of the NHS, Aneurin Bevan, praised the "preventive health services (...) because it is obviously preferable to prevent suffering than to alleviate it» ${ }^{2}$. Sixty years on however, the NHS has not

1. Ministry of Health. A National Health Service. London: HMSO; 1944.

2. Bevan, Aneurin. In place of fear. London: Heinemann; 1952, p. 73. 
lived up to this early aspiration. Indeed, such has been the imbalance of resources between curative and preventive activities that the description of the NHS as a «national sickness service» is a commonplace ${ }^{3}$. Tellingly, the current governmental enthusiasm for public health was prompted mainly by Treasury arguments that improvements in health promotion and disease prevention would reduce future expenditure ${ }^{4}$. This recent resurgence of interest serves only to remind that despite the periodic urging of critics, public health has always played second fiddle within the NHS to a hospital-centred approach. Why should this have been so, despite the rhetoric of those who set up the service in the 1940s?

Part of the answer may lie in the performance of public health medicine in the interwar period, and the state of the specialty as it entered the NHS. At this time its organisational setting was in local government, with the state establishing the legal framework and supplying some devolved funding to support action in priority areas. The local authorities, of which the County Councils and the County Boroughs (the largest towns) were the most significant, provided a broad range of environmental and personal health services under the leadership of public health doctors, the Medical Officers of Health (MOsH). The historical evaluation of interwar public health within local government has proven a controversial subject. In the eyes of early commentators this was a «golden age», when the accretion of powers by the $\mathrm{MOH}$ permitted an unprecedented integration of preventive medicine with curative services ${ }^{5}$. Others have argued that the performance of interwar public health contrasted poorly with its Victorian heyday, and presaged its decline and fall under the NHS.

The present article will discuss this contested historical judgement. Its focus is the activities of local government public health departments under the leadership of the $\mathrm{MOH}^{6}$. After some introductory detail on local public health functions the historiography of the subject is described, attending

3. Wanless, Derek. Securing good health for the whole population, final report. London: HMSO; 2004, p. 38.

4. Department of Health. Public Health White Paper Choosing health: making healthy choices easier. Cm 6374. 2004; Wanless, Derek. Securing our future health: taking a long-term view, final report. London: HM Treasury; 2002, p. 119.

5. Francis, H. Public health: the decline and restoration of the tradition. In: Warren, Michael; Francis, Huw, eds. Recalling the Medical Officer of Health: writings of Sidney Chave. London: King Edward's Hospital Fund; 1987, p. 133-64 (133).

6. I largely leave aside questions of national policy and the academic literature on public health. 
particularly to the criticisms developed by Jane Lewis and Charles Webster. The next section asks how well these criticisms stand up in the light of recent analyses of population health in interwar Britain. There then follows a detailed study of public health administration in a region of the South West of England, which is used to test assertions about national trends. The conclusion is that the more pessimistic readings of the «failure» of interwar public health are in some respects unwarranted.

\section{Public health in Interwar local government}

The making of the public health apparatus of modern Britain is commonly traced to the Public Health Acts of 1848, 1872 and 1875. The former permitted local authorities to appoint a Board of Health to implement sanitary improvement; the later acts made the $\mathrm{MOH}$ appointment compulsory and heralded an expansion of the remit, to include the notification of diseases and the establishment of isolation hospitals, principally for scarlet fever, diphtheria and smallpox ${ }^{7}$. Investment in the sanitary infrastructure gradually accelerated, with a major phase of municipal infectious diseases (ID) hospital building between 1897 and $1907^{\circ}$. Even after the introduction of a national health insurance scheme in 1911 the British state continued to devolve health powers to the local authorities, the rationale being that knowledge of local circumstances was essential to service delivery.

Action focused first on the health of mothers and children, driven politically by imperialist and eugenicist concerns epitomised in the panic over the ill-health of military recruits during the Boer War. A school medical service (SMS) was set up to provide periodic inspections and subsequently some follow-up care; infant welfare clinics were funded, organised by local authorities or charities; provision for childbirth and maternity care included health visiting, ante-natal clinics, supervision of midwives and public maternity beds. The obligation to provide a salaried midwife service was

7. Harris, Bernard. The origins of the British welfare state: social welfare in England and Wales, 1800-1945. Basingstoke: Palgrave; 2004, p. 108-113.

8. Bell, Frances; Millward, Robert. Public health expenditures and mortality in England and Wales 1870-1914. Continuity and Change. 1998; 13 (2): 221-249; Sheard, Sally. Reluctant providers? The politics and ideology of municipal hospital finance 1870-1914. In: Gorsky, Martin; Sheard, Sally, eds. Financing medicine: the British experience since 1750 Abingdon: Routledge; 2006, p. 112-29 (120). 
introduced in $1936^{9}$. Concern over tuberculosis (TB) as a cause of poverty prompted the establishment of a TB service from 1912, which included notification and public dispensaries and sanatoria ${ }^{10}$. Wartime scares over sexually transmitted infections encouraged the funding of venereal disease (VD) clinics from 1917. Insanitary and overcrowded housing was tackled by subsidies in the interwar period which sustained programmes of slum clearance and council house building ${ }^{11}$.

Health powers were also exercised by Poor Law unions, which were spatially and administratively distinct and run by Boards of Guardians. Mental health was one such function, and the Guardians both accommodated psychiatric patients in workhouses and funded their care in asylums managed by local government. Acts of 1913 and 1927 allowed local authorities to provide institutions for «mental deficiency» (today termed «learning disability») ${ }^{12}$. The Poor Law also provided domiciliary medical care as an aspect of «out-relief», and hospital accommodation for the physically ill, particularly long-stay patients rejected by the voluntary sector hospitals. In addition to mixed workhouses many large cities opened separate Poor Law infirmaries.

This division of responsibilities was ended by the 1929 Local Government Act (LGA), which dissolved the Poor Law Unions. Public Assistance Committees were established in the County Boroughs and County Councils to take on many ex-Poor Law responsibilities. The Act also aimed to integrate all local health duties, since it was thought that the stigma of pauperisation associated with Poor Law services was a deterrent to utilisation. Thus not only hospitals but also some maternity, TB and mental deficiency facilities were transferred to Public Health Committees. As a result many ex-Poor Law infirmaries in the larger cities were developed as municipal general hospitals, offering acute in-patient care, hitherto the remit of the voluntary hospitals ${ }^{13}$.

9. Political and Economic Planning (PEP). Report on the British health services. London: PEP; 1937, ch. IV.

10. Bryder, Linda. Below the magic mountain: a social history of tuberculosis in twentieth-century Britain. Oxford: Clarendon Press; 1988, p. 36-45.

11. Harris, n. 7, p. 178, 243-261.

12. PEP, n. 9, p. 273, 276-278.

13. Levene, Alysa; Powell, Martin; Stewart, John. The development of municipal general hospitals in English county boroughs in the 1930s. Medical History. 2006; 50: 3-28. 
To summarise, there was a gradual accumulation of local government public health duties from the mid-nineteenth century, reaching its apogee in the 1930s. By then "public health» had become a capacious term. In the annual statistical taxonomy of local authority spending it signified both environmental and personal health services, though not Poor Law medicine or housing. However, both these aspects regularly featured in the reports of $\mathrm{MOsH}$ and were part of their brief. Nor did contemporaries distinguish clearly between preventive and curative services. Bevan's use of the term «preventive» medicine ranged in scope from the literal understanding as: «(h)ousing, water, sewerage, river pollution prevention, food inspection», to its broadest sense as universal access to curative services: «Preventive medicine (...) is merely another way of saying health by collective action» ${ }^{14}$. This imprecision continued under the NHS, with the Acheson Report of 1988 describing public health as: «the science and art of preventing disease, prolonging life and promoting health through the organised efforts of society» ${ }^{15}$. These wide-ranging and ambiguous definitions should be borne in mind in the discussion which follows. There has never been a consensus on what the term «public health» signifies.

\section{The historiography of interwar public health}

Historically-minded public health practitioners in the interwar period saw their accrual of statutory powers as a progressive phenomenon, starting with the community-oriented environmental work of sanitarians, then moving to services protecting the individual ${ }^{16}$. From this perspective, the extension of powers to include hospitals was a natural evolution, permitting the integration of institutional care with other public health services ${ }^{17}$. Such

\footnotetext{
14. Bevan, n. 2, p. 73-75.

15. Public health in England: The report of the committee of inquiry into the future development of the public health function. (Acheson Report) Cm.289. London: HMSO; 1988.

16. Harley Williams, J. A century of public health in Britain 1832-1929. London: A\&C Black Ltd; 1932, ch. IX; Parlane Kinloch, John. The meaning of an adequate health service. Transactions of the Royal Sanitary Association of Scotland. 1929; 1-12; Middleton Martin, J. Poor law reform and public health. British Medical Journal, 28 Aug 1926; 376-80; Middleton Martin, J. The problem of medical services. Contemporary Review. 1922; 364-372.

17. Parlane Kinloch, John. Reform of the hospital services in Great Britain. The Journal of State Medicine. 1930; 38: 190-191.
} 
views were shared by postwar public health historians. Fraser Brockington depicted advance «at a great rate» through innovative legislation, and growing understanding of the «social aspects of disease» evidenced by the more humane treatment of Poor Law patients, concern over nutrition and new approaches to $\mathrm{TB}^{18}$. Sidney Chave similarly represented the 1929-48 period as the «peak» of the MOH's career, when he was «at the height of his power»; for him the addition of hospital management to the accumulating mix of environmental and personal services was the culmination of a march of progress ${ }^{19}$.

A more critical historiography appeared in the 1980s. The key works are by Lewis, who argues that a growing «divorce between theory and practice» in the interwar years left public health weakened on the eve of the NHS ${ }^{20}$. She suggests that practitioners developed no clear philosophy of preventive medicine, instead adopting an «ex post facto rationalisation» that incorporated duties such as clinical and hospital work which the state had conferred ${ }^{21}$. The impact of germ theory, Lewis suggests, had been to shift public health from environmentalism to personal prevention, thus depriving it of its social and political force. This impetus might have been recovered had the profession embraced the new discipline of «social medicine» championed from the late 1930s by academics like John Ryle. This gave a central place to epidemiology and focused on social causes of disease rather than personal behaviour. However, such a reorientation did not occur ${ }^{22}$. MOsH, she claims, neglected their roles as «community watchdog», for example failing to publicise the deleterious health effects of the economic slump. Innovation came instead from the voluntary sector or from medical entrepreneurs, such as Drs Williamson and Pearse who ran the Pioneer Health Centre in Peckham ${ }^{23}$. Also, the increase in clinical work meant there was increasingly little to distinguish public health medicine

18. Brockington, C. Fraser. A short history of public health. London: J.A.Churchill Ltd.; 1956, p. 4851.

19. Chave, Sidney. The rise and fall of the medical officer of health. In: Warren, Francis eds., n. 5, p. 115-130 (127).

20. Lewis, Jane. What price community medicine? The philosophy, practice and politics of public health since 1919. Brighton: Wheatsheaf; 1986, p. 15.

21. Lewis, n. 20, p. 3, 8, 16.

22. Lewis, n. 20, p. 4-7, 15-17.

23. Lewis, Jane; Brookes, Barbara. The Peckham Health Centre (PEP), and the concept of general practice during the 1930s and 1940s. Medical History. 1983; 27 (2): 151-61. 
from general practice ${ }^{24}$. School medicine, along with hospital and sanatorium administration, preoccupied $\mathrm{MOsH}$ to such an extent that preventive work was ignored. Lewis notes the case of diphtheria immunisation, where Britain, clinging to an established policy of institutional isolation, lagged behind other Western nations which drove down mortality through vaccine programmes ${ }^{25}$. The stubbornly high maternal mortality rates (MMRs) were another failing, even though isolated examples of best practice, such as $\mathrm{MOH}$ Andrew Topping's work in Rochdale, proved what could have been achieved ${ }^{26}$. This was a celebrated case: when Topping arrived in the Lancashire town its MMR was amongst the worst in the country, and between 1930 and 1932 he implemented a reform programme, establishing ante-natal classes and health promotion for mothers, creating a select list of municipal midwives, appointing a consultant from Manchester, and opening a maternity unit at the municipal hospital. MMRs duly fell from 7.82 in 1931 to 1.76 in $1932^{27}$.

Some of these points are amplified in Webster's critique, which concentrates particularly on the failure of public health officials to address the impact of unemployment on child and maternal health. He argues first that national statistical indicators of health improvement, notably falling infant mortality rates (IMRs), obscured major regional and small area variations. These demonstrate that social class differentials remained significant and that joblessness exacerbated malnutrition ${ }^{28}$. The culpability of MOsH lay particularly in their failure to publicise or properly to document the extent of poor nutritional status of schoolchildren or mothers. Only a few mavericks, such as G.C.M'Gonigle, MOH for Stockton-on-Tees, spoke out against the optimistic consensus approved by the Ministry of Health, or bucked the trend of retrenchment by freely distributing nutritional supplements ${ }^{29}$. Webster contrasts this complicity with the forthright political engagement

\footnotetext{
24. Lewis, n. 20, p. 17, 30-33.

25. Lewis, n. 20, p. 28-30; Lewis, Jane. The prevention of diphtheria in Canada and Britain 1914-1945. Journal of Social History. 1986; 20 (1): 163-176.

26. Lewis, n. 20, p. 33; Lewis, J. The politics of motherhood: child and maternal welfare in England, 1900-39. London: Croom Helm; 1980, p. 151-154.

27. Topping, Andrew. Maternal mortality and public opinion. Public Health. July 1936, p. 342349.

28. Webster, Charles. «Healthy or hungry» thirties? History Workshop Journal. 1982; 13: 110-129.

29. Webster, n. 28, p. 112-13; Webster, Charles. Health, welfare and unemployment during the depression. Past and present. 1985; 109: 204-230; and Medical officers of health-for the record. Radical Community Medicine. 1986; 10-14.
} 
of Victorian pioneers like Chadwick and Snow, who placed public health at the centre of policy debate ${ }^{30}$. Like Lewis, he sees the extension into health service administration as a wrong turn, arguing that institutionalisation (presumably in tuberculosis sanatoria and «mental deficiency» colonies) was neither «economical» nor «humane» ${ }^{31}$. He also argues that public health remained vulnerable because of its position within local government, where success depended on an effective $\mathrm{MOH}$ who also enjoyed political support, a strong local tax base and a co-operative voluntary sector. If these were lacking significant regional disparities were bound to follow, particularly in a context of economic retrenchment ${ }^{32}$.

Some subsequent work is situated within the Lewis/Webster paradigm, emphasizing the gulf between the genuinely healthy public policy which might have been achieved and that which actually obtained. For example, Marjaana Niemi's study of MCW and TB in Birmingham argues that scientific findings which implicated poverty and poor housing were discarded in favour of others which legitimised strategies congenial to the existing social order: surveillance, education and segregation ${ }^{33}$. By contrast, John Welshman aims to refute the Lewis/Webster critique with his case study of Leicester. Here the science of diphtheria immunisation was appreciated and a vaccine programme implemented, the new findings on nutrition were incorporated into analysis and policy, the role of poverty in disease aetiology was accepted, and hospital administration did not distract from other activity ${ }^{34}$. More recently Martin Powell and John Stewart have analysed the financing and administration of the local government health system. Using the annual statistical returns of County Borough expenditure on selected aspects of public health they demonstrate comprehensively the degree of spatial variation at the level of both city and region ${ }^{35}$. To some extent this confirms Webster's pessimistic

\footnotetext{
30. Webster, Charles. Public health in decline. Healthmatters. 1992; 11: 10-11.

31. Webster, n. 30.

32. Webster, n. 29, 1986.

33. Niemi, Marjaana. Public health and municipal policy making: Britain and Sweden, 1900-1940. Aldershot: Ashgate; 2007.

34. Welshman, John. The medical officer of health in England and Wales, 1900-1974: watchdog or lapdog? Journal of Public Health Medicine. 1997; 19: 443-450; and: Welshman, John. Municipal medicine: public health in twentieth century Britain. Bern: Peter Lang; 2000.

35. Levene, Alysa; Powell, Martin; Stewart, John. Patterns of municipal health expenditure in interwar England and Wales. Bulletin of the History of Medicine. 2004; 78: 635-669.
} 
account of unevenness and inequity, but Powell and Stewart's verdict is more positive. They argue that the rise in real spending on health must indicate qualitative improvement, and, implicitly, that some variation is a desirable feature of localism: the capacity for individual cities to make their own «investment choices» ${ }^{36}$.

The debate therefore remains a live one. The next section will argue that recent work on interwar population health tends to undermine the critical accounts of the performance of public health. In the subsequent section I will add a regional case study to those others noted above, and will argue that, like Welshman's, it does not conform well to the Lewis / Webster framework.

\section{Public health and population health}

One obvious difficulty with the pessimist case is that several key indicators of population health in interwar Britain showed positive trends. The overall improvement is best exemplified by the long-run decline in IMRs. After remaining high during the nineteenth century (peak years included 1846 [164] and 1899 [163]) IMRs began to fall in the twentieth. The quinquennial average for 1920-25 was 75.8, dropping to 67.8 in 1926-30, then 61.8 in 1931-5 and 55.6 in 1936-40. The decline of infectious diseases, traditionally the concern of public health, played a major part in this, though the precise detail is uncertain given the changing classifications of disease ${ }^{37}$. Put crudely, in the mid-nineteenth century about one in three deaths was thought to be caused by infectious diseases, while by 1900 the figure was about one in 5 , and by the 1960 s it had become «insignificant» ${ }^{38}$. In the County Boroughs of England and Wales for instance, mortality rates from infectious diseases declined from 35.75 in 1922/3 to 21.51 in 1936/7, within which TB mortality fell from 9.42 to $6.12^{39}$.

36. Levene, Alysa; Powell, Martin; Stewart, John. Investment choices? County borough health expenditure in inter-war England and Wales. Urban History. 2005; 32 (3): 434-458.

37. Griffiths, Clare; Brock, Anita. Twentieth century mortality trends in England and Wales. Health Statistics Quarterly. 2003; 18: 5-16.

38. Galbraith S; McCormick, A. Infection in England and Wales. In: Charlton J;. Murphy M, eds. The health of adult Britain. Vol. 2, London: The Stationery Office; 1997, p. 1-20 (3).

39. Registrar General's Statistical Review of England and Wales. London: HMSO; 1922 No 2, 1923 № 3, 1936 № 16, 1937 № 17; infectious diseases = enteric fever, measles, scarlet fever, 
Webster counters that against this picture of advance must be set the persistence of regional and social class inequalities, which were exacerbated by the slump and associated poverty. However, Jay Winter has disputed this, claiming that even in deprived areas the national gains were discernible and inequalities were narrowing. He attributed this to the state welfare system which provided both financial benefits and public health support, notably the MCW service ${ }^{40}$. With Webster arguing principally from the experience of the depressed areas, and Winter comparing selected Metropolitan and County Boroughs, the debate remained unresolved. However, since the early 1980 s several interventions have tipped the argument towards Winter's «optimist» position.

Clive Lee analysed IMRs by county for census years between 1861 and 1971 to discover whether inequality between places was rising or falling. He discovered that variations between county IMRs increased up until 1921 (because those in some places began falling earlier than others), remained almost the same (though marginally higher) in 1931, but fell after this. Thus the period of the slump appears to have been characterised by convergence rather than divergence of the depressed areas, and Lee attributes this to rising prosperity and improved housing from the $1920 \mathrm{~s}^{41}$. Working with a much smaller geographical sample, Bernard Harris's anthropometric study similarly showed that in the poorest towns, where health standards were already low, benefit levels sustained moderate improvement in the stature of children during the 1930s (although Harris argues that rising unemployment did impact on height in four moderately prosperous towns) ${ }^{42}$. More recently Humphrey Southall and Peter Congdon have refined the analysis of the spatial relationship between IMRs and socio-economic indicators to an unprecedented, and presumably unsurpassable, level of detail, with data for

whooping cough, diphtheria, influenza, tuberculosis, bronchitis, pneumonia, diarrhoea, puerperal mortality; TB mortality rate calculated from «Respiratory» + «Other» TB; figures are averaged for $1922+1923$, and $1936+1937$

40. Winter, J. Infant mortality, maternal mortality, and public health in Britain in the 1930s. Journal of European Economic History. 1979; 8 (2): 439-462.

41. Lee, C. Regional inequalities in infant mortality in Britain, 1861-1971: patterns and hypotheses. Population Studies. 1991; 45: 55-65.

42. Harris, Bernard. Unemployment, insurance and health in interwar Britain. In Eichengreen B; Hatton T., eds. Interwar unemployment in international perspective. Dordrecht: Kluwer; 1988, p. 149-183. 
1,770 local government districts ${ }^{43}$. Incorporating variables for population density, occupational structure, overcrowded housing and unemployment levels in a multi-level modelling exercise, they find that unemployment rates did not lead to widening inequalities in IMRs between districts, 1927-36, thus supporting Winter's position. Housing quality however, was associated with diverging IMRs, and they also discern a hitherto unnoticed «mortality excess (...) in more remote, low density, rural areas», which may relate to inaccessibility of MCW provision ${ }^{44}$.

Regional studies can still support elements of the pessimist case, as in Thompson's analysis of South Wales, which compares regional ageand sex-specific mortality with that for England and Wales, finding that for most age groups they worsened in the early 1930s, and that women's disadvantage also increased ${ }^{45}$. IMRs too were diverging from the national mean in some districts, although Thomson makes no systematic attempt to explain these patterns using socio-economic variables and thus mounts no challenge Southall and Congdon's conclusion ${ }^{46}$. Indeed, he argues that the strong social class gradient in IMRs was «the product of a specific social, economic and ecological environment as much as of the economic depression ${ }^{47}$.

In sum, these recent findings on the spatial convergence of IMRs during the 1930s are not obviously compatible with the argument that public health departments were failing. That said, the implication of poor housing quality in the «diverging» districts directs attention to this aspect of local government work: perhaps it was here that health department failure really lay? Future research may determine whether this was the case. Again, Thompson's study of South Wales is suggestive. Here major variations in public housing programmes existed between districts, relating primarily to the tax base of the authority and to population trends (depopulation was

\footnotetext{
43. Congdon, P; Southall, H. Small area variations in infant mortality in England and Wales in the inter-war period and their link with socio-economic factors. Health and Place. 2004; 10: 363-82.

44. Congdon and Southall, n. 43, p. 376, 378-379.

45. Thompson, Steven. Unemployment, poverty and health in interwar South Wales. Cardiff: University of Wales Press; 2006, p. 199.

46. Thompson, n. 45, p. 220-221, 262-263.

47. Thompson, n. 45, p. 245.
} 
a disincentive to building), rather than the commitment of public health officials ${ }^{48}$.

Another important element of Lewis and Webster's critique relates to MMRs, which remained high until the mid-1930s. In absolute terms this cause of death was not numerous: in 1922/1923 there were on average 12.9 deaths from puerperal complications in the County Boroughs, against 24.3 from whooping cough, 29.9 from measles, 177.2 from bronchitis, 186.2 from pneumonia, and 196.6 from TB. None the less, the failure to address this does appear to be an indictment of local government MCW services. Again recent findings do not fully support this. Irvine Loudon's 1992 study of maternal mortality is the definitive work and this apportions culpability more widely, noting the cavalier and sometimes incompetent home deliveries by GPs, the low standard of obstetrical education, the poor distribution of specialists and the lack of integration of services across public, voluntary and private sectors ${ }^{49}$. When improvement finally came, the causes appear to have been a decline in the virulence of streptococcal infection, greater co-operation between GPs, midwives and obstetricians through service integration, and clinical advances in the form of sulphonamides, penicillin and blood transfusion ${ }^{50}$. However, while acknowledging that $\mathrm{MOsH}$ were often circumscribed by skimping local authorities, Loudon does also criticise the absence of strong leadership both nationally and locally.

His only clear evidence for $\mathrm{MOH}$ failure is the totemic Rochdale case, and the familiar claim that other areas could have mounted a successful campaign on the model of Andrew Topping's ${ }^{51}$. The appeal to this wellpublicised case study is not particularly convincing. Rochdale was a small city and its absolute numbers of maternal deaths, ranging annually between 2 and 15 in the period, were so few that they could have been determined by factors which were not systemic, as Topping acknowledged ${ }^{52}$. The Rochdale MMR also fluctuated wildly. In 1924, pre-Topping, it fell to 2.07 , while in 1938, post-Topping hit 10.9; in 1934, just post-Topping it stood at 5.98, a touch higher than 5.72 in the pre-Topping year 1926. By 1936-37 Rochdale's

\footnotetext{
48. Thompson, n. 45, p. 118-123.

49. Loudon, Irvine. Death in childbirth: an international study of maternal care and maternal mortality 1800-1950. Oxford: Clarendon Press; 1992, ch. 13.

50. Loudon, n. 49, ch. 15.

51. Loudon, n. 49, p. 272-273.

52. Topping, n. 27, p. 345: «many will appreciate how one or two real 'snags' will push up the rate in a town with just over 1,000 births a year».
} 
MMR had averaged over 5.00 and it ranked a poor 69th out of 83 County Boroughs in England and Wales ${ }^{53}$. It is surely impossible to generalise from this. Interestingly, Topping himself considered inept MOsH only one among several determinants, which also included the prevalence of abortion, poorly trained midwives and consultants too quick to try heroic measures. Though guarded in his comments, he hints that he blames the Rochdale deaths on unskilled GPs, castigating the BMA for claiming that «all their geese are swans», and on the local voluntary hospital: «It is lèse-majesté to even venture to criticise anything that has the magic word 'voluntary' tagged onto it» ${ }^{54}$. Perhaps what the Rochdale case really demonstrates is how difficult it was for health departments to address a problem involving agencies which were outside their direct control.

These considerations all suggest that harsh criticisms of the failure of local public health officials to address the health impacts of deprivation and maternal mortality should be moderated. But can a more positive evaluation of their achievement be advanced? Winter, Southall and Congdon have speculated that a contributory factor in the fall and convergence of IMRs was the expanding MCW services, and although some historians find the elements of surveillance and education in MCW work excessively paternalistic, others emphasize its positive value to paediatrics ${ }^{55}$. In particular, scholars have credited public health departments between 1900 and 1919 with encouraging breast-feeding, promoting safer bottle-feeding and providing food supplements, then, from about 1925, with securing pasteurised milk for mothers obliged to bottle-feed ${ }^{56}$. The case for the success of interwar public health might therefore be strengthened if a positive relationship between falling mortality and expenditure on services such as these could be established.

Recently published data on local authority health expenditure allow a preliminary test of this relationship to be made. Levene, Powell and Stewart have digitised County Borough expenditure data from annual local

\footnotetext{
53. 1936: 3.65 (4 deaths) and 19376.4 (7 deaths).

54. Topping, n. 27, p. 347-348.

55. Niemi, n. 33; Walker-Smith, John. Sir George Newman, infant diarrhoeal mortality and the paradox of urbanism. Medical History. 1998; 42: 347-361.

56. Fildes, Valerie. Infant feeding practices and infant mortality in England, 1900-1919. Continuity and Change. 1998; 13 (2): 251-280 (260-1, 263-7); Atkins, Peter. Mother's milk and infant death in Britain, circa 1900-1940. Anthropology of Food [annual electronic journal] 2003 [cited 20 August 2007]. Available at: http://aof.revues.org/document310.html.
} 
government taxation returns. They examine the varying rates of growth in expenditure between the financial years 1922/3 and 1936/7, to review the consistency or otherwise of the «investment choices» for health care which municipal governments made over the long-term ${ }^{57}$.

Drawing on these data, Table 1 reports the results of a correlation exercise between expenditure in 82 County Boroughs on $\mathrm{MCW}, \mathrm{TB}$, and ID hospitals, and their mortality rates (crude, infant and maternal). The analysis is dynamic, correlating change in expenditure between 1922/3 and $1936 / 7$ with changes in mortality over the same period. To avoid the distorting effect of epidemic years on death rates the averages over two years have been taken, for 1922/1923 and 1936/1937. The statistically significant results (at 5\%) are highlighted in bold, with a negative figure indicating where high or rising spending correlates with low or falling mortality. There is a negative relationship between $\mathrm{TB}$ expenditure and crude death rates, though not with TB mortality, where it appears that generous spenders were also those with high mortality. It is hard to know what to make of this, though it is certainly consonant with the argument that heavy expenditure on TB sanatoria was ineffective and wasteful ${ }^{58}$.

However, the exercise also yields a negative correlation coefficient between levels of spending on MCW and IMRs, which is significant to $1 \%$. Here is an indicator which could support the hypothesis that rising $\mathrm{MCW}$ expenditure was a key factor in driving down infant mortality, and by extension, could lend quantitative support to the claim that the MCW work of health departments had a positive effect on health outcomes. This is no more than a tentative suggestion, and further research building on Levene et al's data, ideally factoring in housing and environmental expenditure too, should shed more light on the relationship between health expenditure and mortality. None the less, it is one further piece of quantitative and demographic evidence inclining to a more optimistic assessment of interwar public health.

57. Levene et al. report these figures not for the tax year, as in the underlying source, but for the calendar year.

58. McFarlane, Neil. Hospitals, housing, and tuberculosis in Glasgow, 1911-51. Social History of Medicine. 1989; 2: 59-85; Bryder, n. 10, p. 197-198, 258-260. 


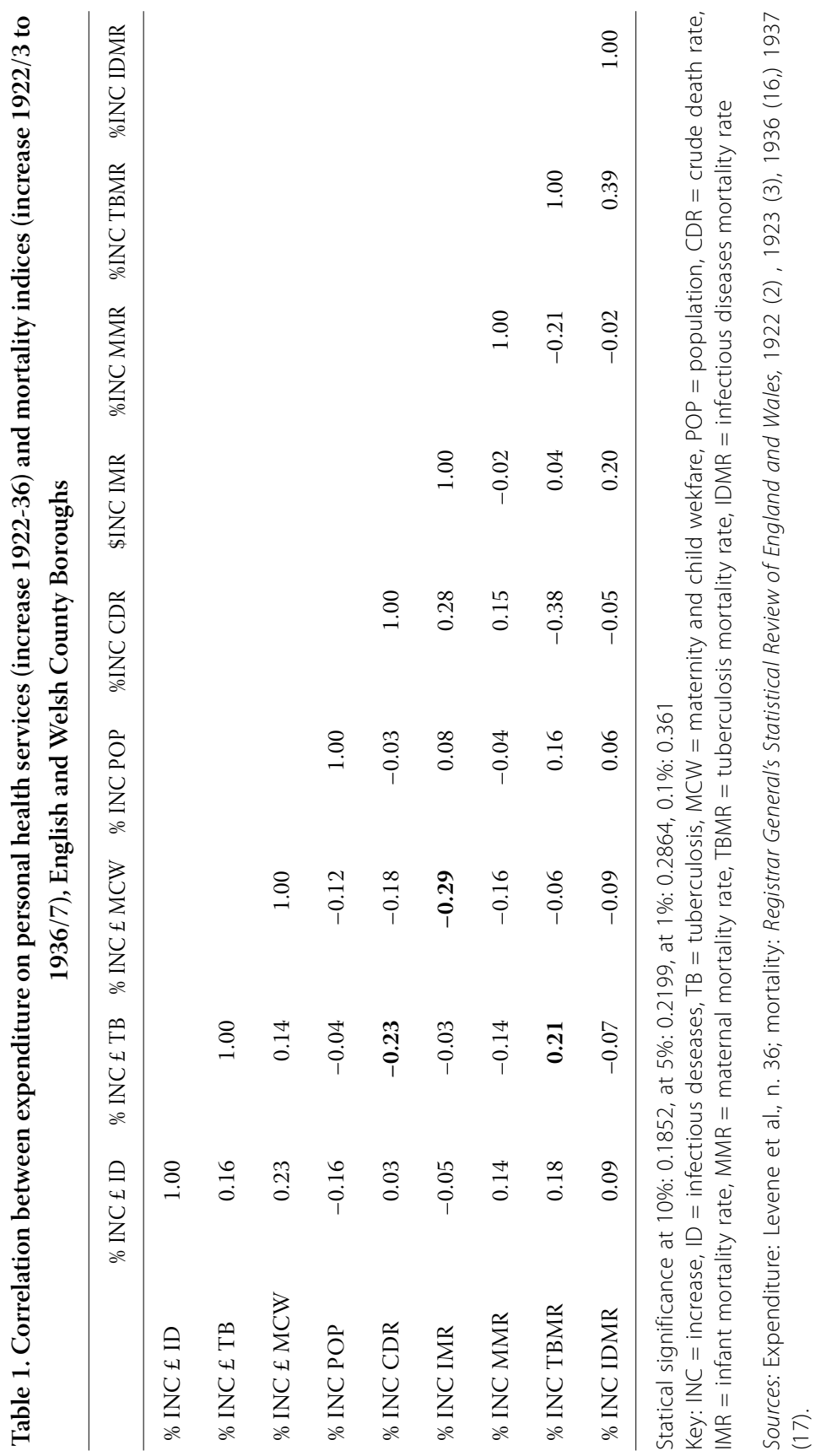




\section{Did Public health fail? A case study from the South-West}

Another approach to assessing the validity of the Lewis/Webster reading is to set it against qualitative evidence of local experience. This section examines public health in a region of the South West of England containing two County Councils, Somerset and Gloucestershire, and three County Boroughs, Bristol, Bath, and Gloucester. Hitherto the detailed work on local government health services has concentrated on cities in the Midlands and North, to the neglect both of Southern cities and counties with sparsely settled rural populations, so this region provides a valuable counterpoint. Pastoral agriculture dominated in Somerset, with its celebrated dairy industry, along with tourism and coal production; Gloucestershire's economy was also agricultural with some coal mining and textiles. Bristol (interwar population c.400,000) was England's seventh largest city and the SouthWest's major outport, as well as a commercial, manufacturing and service centre. Gloucester (c.50,000) was a river port and cathedral city and Bath (c.70,000) a wealthy spa and leisure town.

Taking Lewis's criticism of the failure of diphtheria immunisation first, local sources suggest that action was inhibited by the legacy of popular antivaccinationism ${ }^{59}$. Gloucestershire for example had long been associated with opposition to compulsory vaccination against smallpox, with public protests continuing up until the last epidemic of variola minor, in $1923^{60}$. Meanwhile in Somerset MOH William Savage (who Lewis admires as a «thoughtful commentator») moved slowly for fear that «(...) the «anti» people will whip up a certain amount of opposition» ${ }^{61}$. In Bristol the MOH embraced the science of Schick testing and child immunisation on the American model by the early 1920s, but the political environment inclined the health committee to a voluntary scheme, with resulting low levels of take-up ${ }^{62}$. Moreover in rural areas the powers of public vaccination were situated not

59. Background, see Durbach, Nadja. «They might as well brand us»: working-class resistance to compulsory vaccination in Victorian England. Social History of Medicine. 2000; 13: 45-62.

60. Gorsky, Martin; Mohan, John; Willis, Tim. Mutualism and health care: hospital contributory schemes in twentieth-century Britain. Manchester: Manchester University Press; 2006, ch. 6.

61. Parsons, A. County of Somerset: Further Survey Report The National Archives (TNA) MH 66/215, p. 37; Lewis, n. 20, p. 28.

62. City and county of Bristol Annual Report of the Medical Officer of Health 1924 (BL AR MOH). Bristol; 1925. p. 5-16; BL AR MOH 1934, Bristol; 1935. p. 8-9; by 1934 only about 10\% of Bristol children were immunised. 
with the county council, but with smaller subsidiary authorities, the urban and rural districts. Thus when Gloucestershire's MOH, Kenneth Cowan, initiated a county-wide immunisation scheme this foundered on local resistance. Some districts rejected the scheme, and in others its implementation was remitted to individual GPs who followed inconsistent practices with regard to the numbers of doses ${ }^{63}$. These considerations suggest that it is unreasonable to attribute all blame for Britain's lag in adopting diphtheria immunisation to public health departments. Given the anti-vaccinationist past, it is arguable that only a strong lead from the state would have ensured success, but this was not forthcoming ${ }^{64}$.

Nor is the charge that the relationship between poverty and ill health was ignored during the interwar depression borne out. A striking example is a long essay on the «vicious circle» of poverty in the 1934 report of Bristol's MOH, Robert Parry, in which he implicated lack of «family means» in leading to «slumdom» and poor public health ${ }^{65}$. Nor was there neglect of new research on nutrition. Frustrated with the poor guidance from central government on the classification of malnutrition in school medical inspections, and consequent subjectivity in assessments, Parry initiated a panel study of local 9-year olds. Taking as baseline their classifications as «well» or «poorly» nourished at age 5, researchers conducted physical and mental tests on the children and interviewed their parents, concluding that «we can unhesitatingly say that it is the economic state of the family» which explained malnutrition ${ }^{66}$. This hardly tallies with Lewis's assumption that the «community watchdog» role was neglected. One might also expect, if Lewis's judgement is correct, to find that Parry was an enthusiast for social medicine. But although he was a supporter of Ryle, he regarded social medicine as «(m)ere change of name», and essentially similar to "preventive medicine» in which he held the university chair at Bristol ${ }^{67}$.

Lewis's argument that the activities of public health doctors were becoming increasingly indistinct from those of general practitioners is also

63. Gloucestershire County Council, Annual Report of the Medical Officer of Health for the Administrative County of Gloucester for 1938, (GCC AR MOH). Gloucester; 1939.

64. See also Welshman, n. 34, 1997, p. 445.

65. BL AR MOH. 1934; Bristol; 1935. p. 3, 6.

66. BL AR MOH. 1937; Bristol; 1938. p. 298-312.

67. Parry, R. Some thoughts on the future of public health and of the M.O.H. Public Health. 1948; March: 102-104 (p. 102); Parry, R. The need for overlapping. The Lancet. 1955; March: 609610. 
hard to validate. One obvious difference was that environmental health remained within the MOH's remit in the interwar period. Historians have hitherto neglected this, assuming that practical aspects of the work had been devolved to the sanitary inspector's teams, but the MOH still retained overall direction ${ }^{68}$. Some issues were relatively minor. In Gloucester for example the health department fought a long-running battle in the 1920s to persuade a parsimonious council to provide metal dustbins for waste collection ${ }^{69}$. Elsewhere though, the nineteenth-century struggle to provide constant supplies of fresh running water continued. In Somerset for example, $\mathrm{MOH}$ William Savage moved quickly to identify places which still lacked mains connections, after the County Council gained powers from district authorities in 1929. Levels of funding were raised and regional planning was introduced, though even in the 1940s some dairy farming areas still relied on springs and wells ${ }^{70}$.

More generally, the $\mathrm{MOsH}$ in the five authorities regarded housing improvement as a major health priority. Again the sanitary inspectorate was the workforce, but it was the $\mathrm{MOH}$ who was: «the centre of the stage, the author of the plot and "villain" of the piece, as the principal witness and the butt of cross-examination» ${ }^{71}$. In rural areas an active programme of visiting by the $\mathrm{MOH}$ and housing inspector preceded demolition of «hovels and quite insanitary houses», while health officials advocated the building of low rent public housing and attacked overcrowding ${ }^{72}$. In the cities the $\mathrm{MOH}$ was involved in inspection, slum clearance, the issuing of improvement and closure notices, and the planning of public building programmes. «Of all the causes which tend to undermine the health of the people», stated Bath MOH, James Blackett, in his 1920 report to the council, «a shortage of suitable housing accommodation is by far the greatest». His argument was that damp and overcrowding led to TB, the spread of infectious diseases and high infant mortality. Thus, even in prosperous Bath, health officials highlighted social determinants of morbidity, and used the housing sections of annual reports to encourage local politicians to initiate

\footnotetext{
68. The notable exception is Thompson, n. 45, ch. V.

69. Annual Reports of the Medical Officer of Health for the City and Port of Gloucester, 1920 (GCB AR MOH). Gloucester; 1921.

70. Somerset County Council, Report of the Medical Officer of Health for the year 1929, (SCC AR MOH). p. 42-43; SCC AR MOH 1930, p. 35-69; SCC AR MOH 1945, p. 31.

71. Fawcett, H. The medical officer's practice of housing. Public Health. 1935; October: 6-19, p. 6.

72. SCC AR MOH. 1936; p. 48-49.
} 
improvement ${ }^{73}$. As to the scale of these initiatives, consider the example of Bristol. In the mid-1930s the health department conducted about 1,400 housing inspections annually, with a yearly average of 980 houses found unfit for habitation ${ }^{74}$. Overall the interwar corporation built about 15,000 new houses, of which about $25 \%$ were for families removed through slum clearance $^{75}$.

By coincidence, one of Lewis's key witnesses for the argument that MOsH were losing their preventive role was based in the region. She notes the criticism which William Savage, MOH for Somerset, launched in 1935 of the administrative burdens imposed by the LGA, which he saw as «not our proper business» ${ }^{76}$. Hospital work and responsibility for mental health, he argued, detracted from the development of new preventive strategies, and Lewis concludes from this that MOsH were failing to keep abreast of new practices and remained wedded to traditionalism ${ }^{77}$. Was Savage's analysis reliable, and his perspective representative? Consideration of his long and distinguished career in Somerset (1909-1937) suggests not. Born in 1873 he was close to retirement by 1935 , describing himself as «an old timer bred in the old tradition». His public health textbook of 1941 demonstrates that his goal was not to reinvent preventive medicine, but to preserve for the $\mathrm{MOH}$ the time-honoured environmental duties increasingly devolved to sanitary inspectors ${ }^{78}$. Indeed, a Ministry of Health surveyor in 1931 wrote that Savage was disinclined to delegate and was unusually committed to environmental health, functioning as a «sort of super sanitary inspector» ${ }^{79}$. His substantial published output in the 1930s confirms this orientation, dealing predominantly with issues of milk and food safety and bovine tuberculosis (matters close to his heart in cheese-producing Somerset), while his textbook concentrated on water supply, disposal of sewage and effluent,

\footnotetext{
73. Annual Report of the Medical Officer of Health and the Chief Inspector of Nuisances for the Year 1920 (BA AR MOH). Bath: 1921, p. 7.

74. BL AR MOH, 1934-1938, passim.

75. Malpass, Peter; Walmsley, Jenny. 100 years of council housing in Bristol, Bristol: University of the West of England; 2005, p. 4-5.

76. Savage, W. Our future. Public health. 1935; 49 (Nov): 42-47.

77. Lewis, n. 20, p. 28.

78. Savage, W. Practical public health problems. $2^{\text {nd }}$ ed. London: J \& A.Churchill; 1941, p. 6.

79. Parsons, A. Administrative County of Somerset: Report on a Survey of Health Services. TNA $\mathrm{MH} / 66 / 210$ p. $12,20-21,125$.
} 
river pollution and housing inspection ${ }^{80}$. Savage may also have been singularly ill-disposed towards the post-LGA administrative duties because of difficulties peculiar to Somerset. His efforts to assert control over the transferred Poor Law institutions in order to «depauperise sickness» were unsuccessful, as was his recommendation that the county should build a new central hospital rather than developing existing stock ${ }^{81}$. These observations point to a potential problem with Lewis's methodology, heavily reliant on articles in the professional journals, which when contextualised may have a different significance.

Claims of administrative «overstretch» are further contradicted by regional evidence that public health departments experimented with new preventive strategies. One example is the advance of health education, then termed «health propaganda». To a limited extent this followed national leadership, with «health weeks» and distribution of journals and posters, but it emanated principally from local initiative. It is ironic in the light of Savage's complaints about bureaucratic distractions that Somerset County Council provides a prime illustration. A full-time worker gave talks to Women's Institutes, Mothers Unions, schools, district nursing associations, village communities, girl guides, boy scouts and so on. Films and a travelling exhibition accompanied these health education efforts, whose explicit rationale was to promote healthy living and counter the ignorance deemed to cause much ill health ${ }^{82}$. Clearly innovative health promotion was not confined to better known «progressive» authorities like Bermondsey ${ }^{83}$. Another example is the use of TB screening programmes which began during wartime. The first step was Bristol's purchase of a «mass miniature

80. Savage, n. 78; the Index Medicus records 28 articles published 1930-39, eg. Pasteurisation in relation to milk distribution. Lancet. 1931; 1: 543-554; Discussion on milkborne streptococcus epidemics. Proceedings of the Royal Society of Medicine. 1931; 24: 111-120; Prevention of human tuberculosis of bovine origin, Journal of the Royal Sanitary Institute. 1933; 54: 11-17; Presidential address on water and sewage schemes in rural areas. Journal of the Royal Sanitary Institute. 1936; 57: 339-345, Ice cream food poisoning outbreak due to B. dysenteriae (Sonne). Journal of Hygiene. 1938; 38: 331-337.

81. Somerset County Council, Public Assistance Committee Minute Book from Dec, 1929. to Dec, 1932, 25 November 1930. SRO C/WS/PA 1; Savage, W. Somerset County Council Health Department: A preliminary report upon the accommodation for the sick and other inmates in poor law institutions in Somerset, February 12th 1930; p. 14.

82. SCC AR MOH ,1935. p. 37; SCC AR MOH, 1937, p. 34-39.

83. Lebas, Elisabeth. «When every street became a cinema». The film work of Bermondsey Borough Council's Public Health Department, 1923-1953. History Workshop Journal. 1995; 39: 42-55. 
radiography unit» used to screen selected groups, such as cohorts of school leavers, council staff, civil servants and BBC radio employees. A van was then purchased, which made the equipment available for temporary loan to the neighbouring authorities, with Bath for example screening government employees in the city ${ }^{84}$. Screening and health promotion assumed greater significance as an activity of local government public health departments under the NHS, but they were rooted in the earlier period.

Behind the critique which Lewis and Webster level is the assumption that interwar public health might have done more to further social justice during the economic recession. Certainly the case is well made with respect to the inadequacy of food supplements in the depressed areas and the failure of public housing adequately to address the needs of the very poor ${ }^{85}$. However, if we turn from a narrow definition of preventive medicine to consider the activities of public health departments more broadly it is possible to discern a significant advance in equity. First, much local government health work was funded through local taxation based on property values, which, with some provisos (related to geographical variations and to exemptions), was increasingly progressive ${ }^{86}$. And while user fees were introduced for some services, they did not loom large as a source of revenue and were not aggressively pursued. For example, in the five South West authorities on average only $8 \%$ of the SMS was funded by recoupments from parents ${ }^{87}$.

Second, the growing range of personal health services meant more equitable access. After 1929 the appropriated municipal hospitals admitted patients for acute medical care on the basis of local citizenship and

84. BL AR MOH, 1944, p. 15-16; BA AR MOH, 1944, p. 26.

85. Although studies by the National Birthday Trust Fund, previously considered robust evidence for the desirability of nutritional supplements in depressed areas, have been shown to have been flawed in design, data collection and reporting: A.Susan Williams, Relief and research: the nutrition work of the National Birthday Trust Fund, 1935-9, Smith, David F., ed. Nutrition in Britain: Science, scientists and politics in the twentieth century. London: Routledge; 1996, p. 99-122.

86. Finer, H. English Local Government. London: Methuen; 1933, p. 393-434.

87. Figures for 1919/20-1944/5, from City of Bath, Abstract of Accounts 1921-45. Bath Record Office; City and County of Bristol: Abstract of the Treasurer's accounts, 1921-47. Bristol Record Office (BRO); Gloucestershire County Council, Abstract of Accounts, 1918-47, City of Gloucester, Abstract of accounts, 1931-44. Gloucestershire Archives; Administrative County of Somerset: An abstract of the accounts of the County Council, 1924-46. Somerset Archives and Record Service. 
they added significantly to the volume of available provision. In Bristol for instance the ex-Poor Law Southmead Hospital rapidly developed from long-stay institution to acute care hospital: 75 per cent of patients stayed for less than four weeks by 1938, and the number of maternity confinements increased from 127 in 1928 to 3,131 in $1942^{88}$. There were also experiments in bringing services to previously under-served rural areas. Gloucestershire initiated an «Extension of Medical Services Scheme», creating a network of «out-stations» in remote places, with regular clinics linked to general hospitals through formal referral networks ${ }^{89}$. In Somerset a different approach was tried, with a system of "flying clinics" (ie without a fixed location) for rural areas. This developed from a series of nurse-led «Mothers and Babies Afternoons» to include a doctor and the health propaganda officer ${ }^{90}$. In the cities similar initiatives were underway. Bristol pioneered the building of health centres aimed principally at infants and children and intended to provide a nexus for MCW and SMS work, to ensure joined-up working and a referral system to underpin inspections ${ }^{91}$. These were not health centres on the Peckham model, but considering the entrenched opposition of private practitioners to any such initiative, they too represented an important extension of access ${ }^{92}$.

Finally, with respect to patient dignity, the removal of many services from the Poor Law lessened the shame of accessing public medical services, and eroded, though did not destroy, the historic division between a «respectable» voluntary sector for the self-supporting and a lesser public sector for the dependent poor. The appropriation of Bristol's Southmead explicitly aimed to «remove the stigma of pauperism» so that the poor would receive «hospital treatment (...) under the same conditions as the rest of the citizens» ${ }^{93}$. Even in the public assistance institutions, oral his-

88. BL AR MOH, 1928. Bristol; 1929; BL AR MOH, 1938. Bristol: 1939; BL AR MOH, 1939-1942. Bristol: 1943.

89. Gorsky, Martin. The Gloucestershire Extension of Medical Services Scheme: an experiment in the integration of health services in Britain before the NHS. Medical History. 2006; 50: 491-512.

90. SCC AR MOH, 1931, p.32.

91. Parry, R. Health centres. Journal of the Royal Sanitary Institute. 1947; 67: 111-120.

92. See Pyrs Gruffudd. «Science and the stuff of life»: modernist health centres in 1930s London. Journal of Historical Geography. 2001; 27: 395-416 for a critical evaluation of Peckham compared to municipal efforts.

93. Health Committee HC, 1/1/1930; Council Minutes, 8/4/1930. BRO. 
tory shows that management styles were becoming more compassionate, professional and progressive ${ }^{94}$.

\section{Conclusion}

Historical assessment of the performance of British public health is to some extent time bound. The «golden age» perspective reflects mid-twentieth century optimism about the potential of a state health service under the paternal guidance of professional experts. The Lewis/Webster critique, by contrast, was formulated in the 1980s when by common consent the public health specialty was in decline ${ }^{95}$. The $\mathrm{MOH}$ post had disappeared in the 1974 NHS reorganisation, to be replaced by the less effective «community physician», who was rapidly swamped with administrative work. Fears of a growing crisis in public health were simultaneously fuelled by the growth of HIV/AIDS and by two food-poisoning outbreaks. This led to the appointment of the Acheson Committee, and ultimately to a revival in the 1990s, with the creation of Director of Public Health posts ${ }^{96}$. Webster and Lewis both gave historical evidence to Acheson and it is unsurprising that they sought to delineate long-run antecedents for the neglect and marginalisation of the specialty within medicine and health policy-making. However, as new work on the subject emerges this reading can be reviewed, and the argument here is that for the interwar period, some revision is due.

The substantive points are as follows. First, the demographic context for any assessment of organised public health should predispose us to a broadly positive verdict. There was a marked improvement in infant mortality, and some supporting evidence that MCW interventions contributed to this. The existence of regional disparities in IMRs remained, but recent findings confirm that these were narrowing rather than growing, despite the depression; maternal mortality remained tragically high but it is far from clear that health departments should shoulder the blame for this. Second,

94. Adams, J. The last years of the workhouse. In: Bornat J. et al., eds. Oral History, health and welfare. London: Routledge; 2000; p. 98-118 (104, 106-107, 112-113).

95. Berridge, Virginia; Christie, D; Tansey, E., eds. Public health in the 1980s and 1990s: decline and rise? London: Wellcome Trust; 2006; Francis, n. 5, p. 133-641.

96. Public Health in England: the report of the Committee of Inquiry into the future development of the public health function (Acheson Report), Cm. 289, London: HMSO; 1988. 
while it is impossible to generalise from limited case studies, analysis of local public health work does not conform well to Lewis's model. The policy goal of the "co-ordination and completion of medical services», with state action drawing together preventive and curative work, was widely shared by contemporaries, and cannot be dismissed as an ex-post facto rationalisation ${ }^{97}$. Far from relinquishing their posts as champions of public health, the activities of some interwar MOsH demonstrate the positive influence of a high profile local health official. It is not obvious that they abandoned their watchdog role, nor that their new remit for curative services distracted them from prevention. Instead they pioneered new forms of service delivery, and under their leadership equity was advanced.

There are then good grounds for a more generous evaluation of public health in interwar local government. Of course, serious criticisms remain, for example over the effectiveness of institutional responses to TB and the treatment of psychiatric patients. These are issues that can be explored in future research, whether through further case studies in the vein of Welshman's or Niemi's, or through analysis of the local government financial data, opened up by Powell and Stewart. This rereading also invites a fresh look at the $\mathrm{MOH}$ and public health departments in the early years of the NHS. If the causes of their eventual decline in the 1970s did not lie in their intellectual and practical failings before 1948, then it is high time that attention focuses on the later period, to establish how they responded to the changing demographic and administrative environment of the 1950s and 1960s.

\section{Acknowledgments}

Research for this article was sponsored by the Wellcome Trust, for whose support I am most grateful. This paper was first presented at the Interwar Health Network workshop «Crises as opportunities in interwar health?» 27-28 april 2007, Granada, and I would like to thank participants at this meeting for their helpful criticism.

97. Newsholme, Arthur. Medicine and the state: the relation between private and official practice of medicine with special reference to public health, London: Allen and Unwin; 1932, p. 34-35, 257-266. 